\title{
Microwave Absorption Properties of Carbon Nanotubes-Epoxy Composites in a Frequency Range of 2 - $20 \mathrm{GHz}$
}

\section{Zhou Wang, Guang-Lin Zhao}

Department of Physics, Southern University and A \& M College, Baton Rouge, Louisiana, USA.

Email: Guang-lin_zhao@subr.edu

Received March $1^{\text {st }}, 2013$; revised March 30 ${ }^{\text {th }}, 2013$; accepted April 10 $0^{\text {th }}, 2013$

Copyright (C) 2013 Zhou Wang, Guang-Lin Zhao. This is an open access article distributed under the Creative Commons Attribution License, which permits unrestricted use, distribution, and reproduction in any medium, provided the original work is properly cited.

\begin{abstract}
In this work, multi-walled carbon nanotubes (MWCNTs)-epoxy composites with MWCNTs (outer diameter less $8 \mathrm{~nm}$ ) loadings from 1 to $10 \mathrm{wt} \%$ were fabricated. The microstructures, dielectric constant, and microwave absorption properties of the MWCNTs-epoxy composite samples were investigated. The measurement results showed that the microwave absorption ratio of the MWCNTs-epoxy composite strongly depend on the MWCNT loading in the composites. The microwave absorption ratio up to $20 \%-26 \%$ around $18-20 \mathrm{GHz}$ was reached for the samples with $8-10 \mathrm{wt} \%$ MWCNT loadings. The high absorption performance is mainly attributed to the microwave absorption of MWCNTs and the dielectric loss of MWCNTs-epoxy composites.
\end{abstract}

Keywords: Microwave Absorption; Multi-Walled Carbon Nanotubes; Epoxy Composites; Absorption Ratio; Dielectric Loss

\section{Introduction}

Microwave absorbing materials are very important for many applications in modern technology including electronics and telecommunications [1]. Microwave absorbing materials are designed to provide electromagnetic shielding and absorption that find their applications in commercial, civilian, and consuming electronic devices applications [2-9]. For example, circuitboard engineers often find that their well-devised circuit board does not operate properly when it is integrated with the shielded cavity or chassis. The resonance in shielded microwave cavities is the increasingly recognized cause of the problem. Microwave absorbing materials can be used as a viable method for dampening microwave cavity resonances. When exposed to an external electromagnetic field, the electrons in the microwave absorbing materials will generate an inductive current which then cause radiation attenuation and energy dissipation. Carbon nanotubes (CNTs) and CNT composites have been emerging as new perspective microwave absorbers due to their fascinating physico-chemical properties such as light-weight, resistance to corrosion, high mechanical strength, larger flexibility and superior electrical performance [6,10-13]. The- oretic and experimental studies have demonstrated that the unique one dimensional hollow tube structures of CNTs enable them to show outstanding electrical properties such as either ballistic transport or diffusive transport, along with long mean free paths [14]. The conjugate $\pi$ electrons are restricted in the one-dimensional cylinder and thereby enable CNTs to show distinctive electronic response and offer CNTs the ability to serve as an emerging microwave absorbing material [15].

Multi-walled carbon nanotubes (MWCNTs)-polymer composites offer a large flexibility for design and control of microwave absorption behaviors, as the composites can be tailored through changes in loading fractions, matrix materials, complex permittivity and loss tangent of MWCNTs-polymer composites $[1,16,17]$. The microwave absorbing properties of the MWCNTs-polymer composites depend on the CNT loading fraction, which can affect the absorption bandwidth and resonance frequency. It was reported that the absorption peak of MWCNTsepoxy composites shifted downward with increasing the MWCNT loading [12]. It is observed that the absorption frequency ranges of single-walled carbon nanotubes (SWCNTs)-polyurethane composites broaden from 6.4 $8.2(1.8 \mathrm{GHz})$ to $7.5-10.1(2.6 \mathrm{GHz})$ and to $12.0-15.1$ 
$\mathrm{GHz}(3.1 \mathrm{GHz})$ as the SWCNTs loadings in the composites decreased from 10 to 5 and to $2 \mathrm{wt} \%$, respectively [18]. Hence, by controlling the loading fraction of the CNT-composites, microwave absorbing response may be tuned in a broad range with strong absorption and wide absorption bandwidth. In addition, the complex permittivity and permeability of MWCNTs-polymer composites are the fundamental physical quantities in determining the microwave properties [19-23]. From the classic transmission line theory, an adjustment of complex permittivity and permeability satisfying the impedance match condition will offer the possibilities to produce light-weight and cost-effective microwave absorbing materials [24].

Among the broad polymer candidates suitable for embedding MWCNTs for preparing the microwave absorbing materials, epoxy is one of the most attractive polymers due to its commercial availability, resistance to corrosion, and relatively easy for processing. Thus, MWCNTsepoxy composites may be used as microwave absorbing as well as protective coating for potential applications. In this work, MWCNTs-epoxy composites with different MWCNTs weight loadings were fabricated by a mechanical stirring method. In the previous publications, we presented the microwave absorption properties of MWCNsepoxy composites at microwave frequencies around $9.968 \mathrm{GHz}$ and $8.43 \mathrm{GHz}$, utilizing a microwave resonant cavity as a probe $[25,26]$. In this study, we focused on the microwave absorption performance of the MWCNTsepoxy composites in a continuous frequency range from 2 to $18 \mathrm{GHz}$.

\section{Experimental}

MWCNTs with outer diameters (OD) less than $8 \mathrm{~nm}$ were obtained from a commercial company (Cheaptubes, USA). The purity of MWCNTs is better than $95 \%$. The ash content in the MWCNTs powder is less than $1.5 \mathrm{wt} \%$. The length distribution of MWCNTs is in the range of 10 $50 \mu \mathrm{m}$. MWCNTs have much higher performance-toprice ratio (PPR) than that of SWNTs for large scale composite applications.

MWCNTs-epoxy composites were fabricated via mechanical mixture methods. The loading of MWCNTs in the composites was controlled from 1 to $10 \mathrm{wt} \%$. Firstly, the epoxy resin (Aero Marine 300/21) and MWCNTs were mixed and stirred in a hotplate magnetic stirrer at $90^{\circ} \mathrm{C}$ for $1 \mathrm{~h}$, where the high temperature was used to reduce the viscosity of epoxy for well dispersion of the mixture. Then, a hardener agent was added into the mixture and stirred for $10 \mathrm{~min}$. Care was taken to reduce bubbles in the mixture by controlling the stirring rate. After that, the mixture was injected into hollow cylinder molds and subsequently transferred to an oven for precuring and post-curing at $80^{\circ} \mathrm{C}$ and $120^{\circ} \mathrm{C}$ respectively.
Both curing processes lasted for 1 hour. The as-obtained O-ring shape samples (the inner and outer diameters of the samples are $1.5 \mathrm{~mm}$ and $3.5 \mathrm{~mm}$, respectively) were carefully cut to yield a uniform thickness of $2 \mathrm{~mm}$. In this experiment, a maximum loading amount of $10 \mathrm{wt} \%$ MWCNTs into the epoxy has been realized, beyond that MWCNTs cannot homogeneously dispersed in the epo$\mathrm{xy}$.

Scanning electron microscopy (SEM) images of the samples were recorded on JSM-6390 (JEOL, Japan) with an accelerate voltage of $5 \mathrm{KV}$. All the samples were coated with a layer of gold for good conductivity. X-radiation Diffraction (XRD) analysis of the samples were performed on MiniFlex 600 (Rigaku, Japan) with $2 \theta$ scanning range from $10^{\circ}$ to $80^{\circ}$.

Both the relative complex dielectric permittivity $\varepsilon=\varepsilon^{\prime}$ $-j \varepsilon^{\prime \prime}$ and magnetic permeability $\mu=\mu^{\prime}-\mu^{\prime \prime}$ were obtained by utilizing Agilent Vector Network Analyzer N5230C (Agilent Company, USA), a coaxial transmission method, and Agilent 85,071 material measurement software for a frequency range from 2 to $20 \mathrm{GHz}$.

\section{Results and Discussion}

\subsection{SEM Morphology}

Figure 1 shows typical scanning electron microscope (SEM) cross-section images of MWCNTs-epoxy composite samples with 1 and $7 \mathrm{wt} \%$ MWCNT loadings. It is known that MWCNTs will spontaneously attract each other to form MWCNTs bundles, due to weak van der Waals forces between them. This is confirmed from Figure 1, in which the MWCNT were aggregated into a few hundred nanometer bundles [18]. The MWCNT bundles are homogeneously dispersed into the epoxy matrix at $1 \mathrm{wt} \%$ MWCNT loading (Figure 1(a)). When increasing the MWCNT loading to $7 \mathrm{wt} \%$ in the composite, the MWCNT bundles formed aggregates and agglomerates with irregular sizes and shapes in the epoxy matrix (see Figure 1(b)).

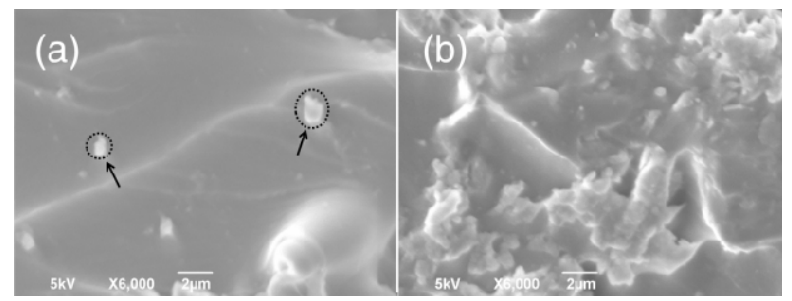

Figure 1. SEM images of the MWCNTs-epoxy composite samples with (a) $1.0 \mathrm{wt} \%$ and (b) $7.0 \mathrm{wt} \%$ MWCNTs, respectively. The blackdash-circles (indicated by arrows) in (a) show typical cross-sections of MWCNT bundles which were uniformly dispersed in the composites. The MWCNTs aggregations (white area in (b)) are formed in the composite with 7 wt \% MWCNTs loading. 


\subsection{XRD Analysis}

In order to investigate the microstructure evolution of the MWCNTs-epoxy composites with different MWCNTs loadings, XRD analysis was performed. Figure 2 shows the XRD patterns of the pristine MWCNTs, pure epoxy, and MWCNTs-epoxy composites. The narrow peak at around $2 \theta=25.6^{\circ}$ in the pristine MWCNT sample is assigned to the reflection of inter-tubes with a spacing $\mathrm{d}=$ $3.430 \AA$, that is slightly larger than the inter-planar spacing $(\mathrm{d}=3.335 \AA)$ of graphite $(002)$. Herein, the broadening of the spacing in the MWCNTs indicate that the interlays of graphitic structure in the MWCNTs were expanded during the preparation process, which were associated with the formation of tubular structure and the development of structural defects. Meanwhile, a weak peak located at $2 \theta=43.4^{\circ}$ in MWCNTs is also observed and is assigned to the reflection of graphite-like structure (100). For the pure epoxy samples, a broad peak centered at $2 \theta=19.5^{\circ}$ is observed which is assigned to the amorphous structure of the epoxy. When adding MWCNTs into the epoxy matrix, this peak shifts towards to higher values and reach to $2 \theta=21.6^{\circ}$ for the MWCNTs-epoxy composites. The upward shifting of this peak in the MWNCTs-epoxy composites clearly shows that the embedding of MWCNTs into epoxy resin influences the microstructure of the composites by the means of interfacial interaction between the MWCNTs and epoxy matrix.

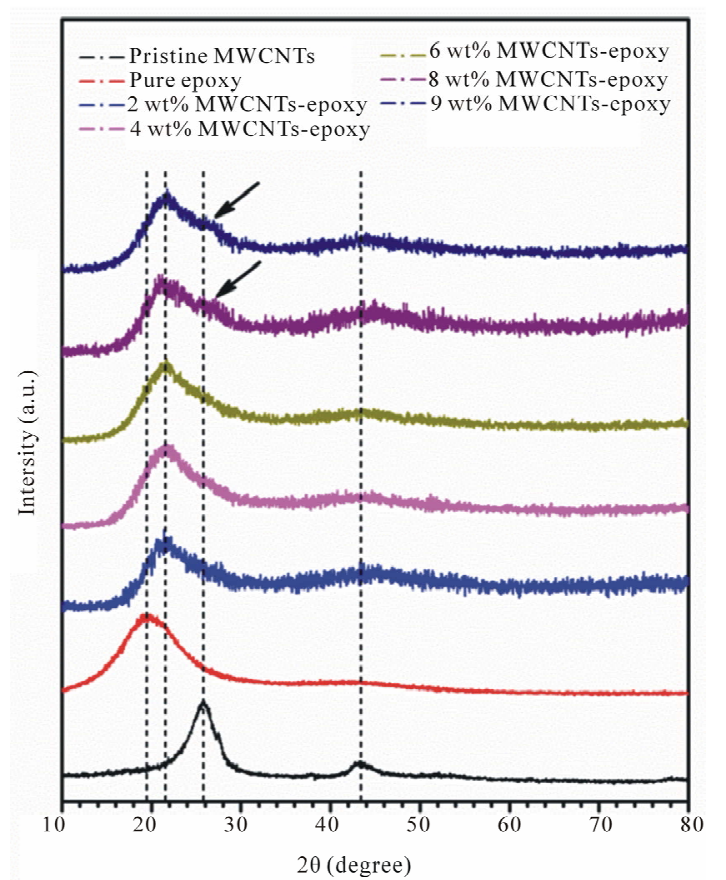

Figure 2. XRD patterns of the pristine MWCNTs, pure epoxy and MWCNTs-epoxy composites at different MW-CNTs loadings. The vertical dash lines are guide for the character- istic peaks of the samples.
However, the characteristic graphite-like (002) peak of MWCNTs is quite weak in the composites with MWCNTs loadings up to $7 \mathrm{wt} \%$. For the MWCNTs-epoxy composite samples with MWCNTs loadings higher than $8 \mathrm{wt} \%$, a minor shoulder structure (indicated by black solid arrows in Figure 2) arises, which is attributed to the characteristics of MWCNTs.

\subsection{Complex Dielectric Permittivity}

The microwave absorption properties of the materials are related to the fundamental physical quantities: relative complex permittivity $\varepsilon$ and permeability $\mu$. In our experiment, both quantities (complex permittivity and permeability) were measured. Figure 3 shows the real part of relative permittivity $\varepsilon^{\prime}$ of the MWCNTs-epoxy samples. Increasing the loading amount of MWCNTs in the composites, the values of the real part of permittivity $\varepsilon^{\prime}$ are increased. The real part of relative complex permittivity $\varepsilon^{\prime}$ showed a slow increase from $\sim 3.0$ to $\sim 4.0$ for the samples with increased MWCNT loadings from 1 to 3 $w t \%$. Further increasing MWCNT loading amount in the epoxy composites, $\varepsilon^{\prime}$ gradually increased to about 8 for $10 \mathrm{wt} \%$ MWCNTs in the composite. $\varepsilon^{\prime}$ also show some frequency dependence from 2 to $20 \mathrm{GHz}$, when the MWCNT loadings in the composites are higher than $3 \mathrm{wt} \%$.

Figure 4 shows the imaginary part of relative dielectric permittivity $\varepsilon^{\prime \prime}$ of the MWCNTs-epoxy composite samples. Increasing MWCNTs loading to $3 \mathrm{wt} \%$ in the composite samples, the values of $\varepsilon^{\prime \prime}$ increase from about 0.1 (pure epoxy) to about 0.3 , and did not show much frequency dependence in the measured range $(2-20$ $\mathrm{GHz}$ ). However, for the composite samples with MWCNT loadings higher than $4 \mathrm{wt} \%$, the values of $\varepsilon^{\prime \prime}$ increase substantially and also show frequency dependence in the experimentally measured region from 2 to 20 $\mathrm{GHz}$. At the higher frequencies, the values of $\varepsilon^{\prime \prime}$ are also

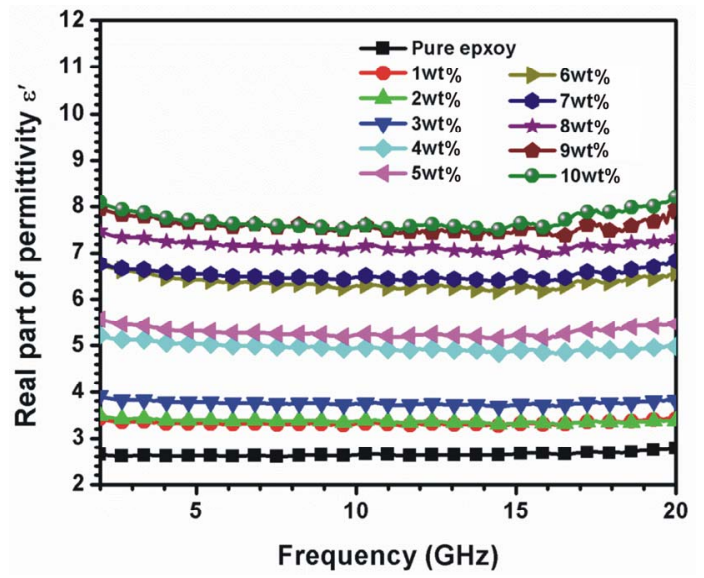

Figure 3. Real part of the permittivity of the MWCNTsepoxy composite samples. 


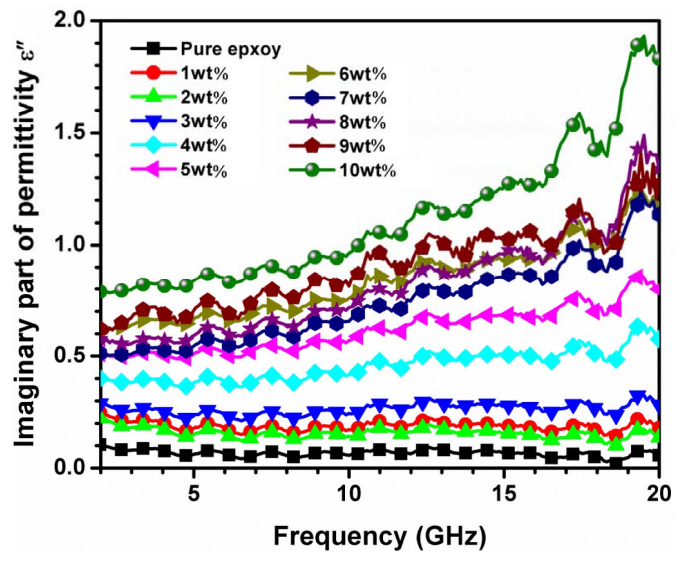

Figure 4. Imaginary part of permittivity of the MWCNTsepoxy composite samples.

higher, especially for the high frequency range from 10 to $20 \mathrm{GHz}$. For example, when the MWCNT loading is $10 \mathrm{wt} \%$ in the composite, the value of $\varepsilon^{\prime \prime}$ is 0.8 at $2 \mathrm{GHz}$, increases to 1.0 at $10 \mathrm{GHz}$, and further rises to about 1.9 at $19 \mathrm{GHz}$. Physically, the real part of relative complex permittivity $\varepsilon^{\prime}$ is a measure of how much energy from an external electromagnetic field can be stored in a material. The imaginary part of relative complex permittivity $\varepsilon$ " represents how dissipative and/or lossy a material is to external electromagnetic field. So that $\varepsilon^{\prime \prime}$ is directly related to the microwave absorption of the material. Herein, our results clearly showed that the ability of the energy storage and microwave absorption in the MWCNTs-epoxy composite samples was substantially enhanced by increasing the MWCNT loadings in the polymer composites.

\subsection{Loss Tangent}

The loss tangent, which is defined as the ratio of $\varepsilon^{\prime \prime}$ to $\varepsilon^{\prime}$, is a measure of energy loss in a material. It is directly related to the attenuation factor to convert stored energy to dissipative heat $[12,27]$. Thus, the microwave absorption improves as the loss tangent increases, due to a higher attenuation factor [28]. Figure 5 shows the loss tangent of MWCNTs-epoxy composites as a function of frequency. The loss tangents slightly increase from about 0.05 to 0.07 as the MWCNTs loadings in the composites increase from 1 to $3 \mathrm{wt} \%$. When the MWCNTs loadings are higher than $4 \mathrm{wt} \%$, the loss tangents are much increased and also show frequency-dependence in the measured frequency range, especially for the high frequency region from 10 to $20 \mathrm{GHz}$.

\subsection{Complex Permeability}

The complex permeability $\mu$ is a measure of microwave absorption properties of the material from magnetic in- teractions. Due to the weak magnetism of both MWCNTs and epoxy resin, the composite samples showed relatively low permeability, where the real part of permeability $\mu^{\prime}$ fall into the range from 1.1 to 1.4 , and the imaginary part of permeability $\mu^{\prime \prime}$ remained at the value of $\sim 0.8$ (Figure 6). The low values of permeability of the composites show that the microwave absorption of the MWCNTSepoxy composites was mainly attributed to the dielectric loss.

\subsection{Microwave Absorption of CNT-Epoxy Composites}

When a microwave radiation is incident on a material surface, its energy is partly reflected, absorbed, and transmitted. The CNT-epoxy composites can attenuate the microwave radiation and absorb its energy. According to the classic transmission line theory, the reflectance (R), absorbance (A) and transmittance (T) can be described as below: $[29,30]$.

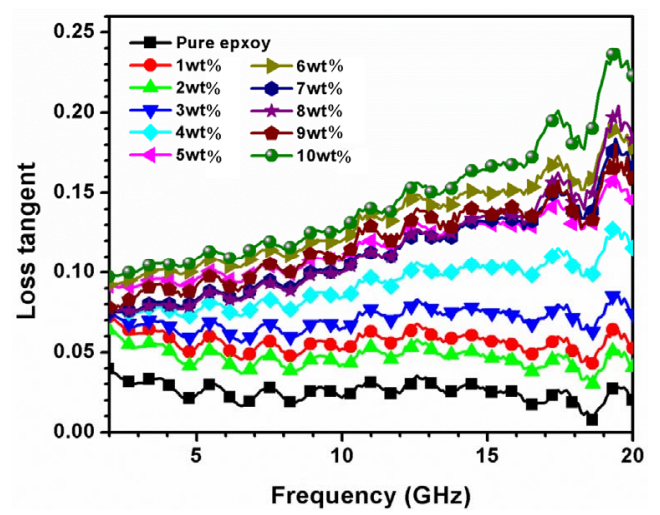

Figure 5. Loss tangent of the MWCNTs-epoxy composite samples.

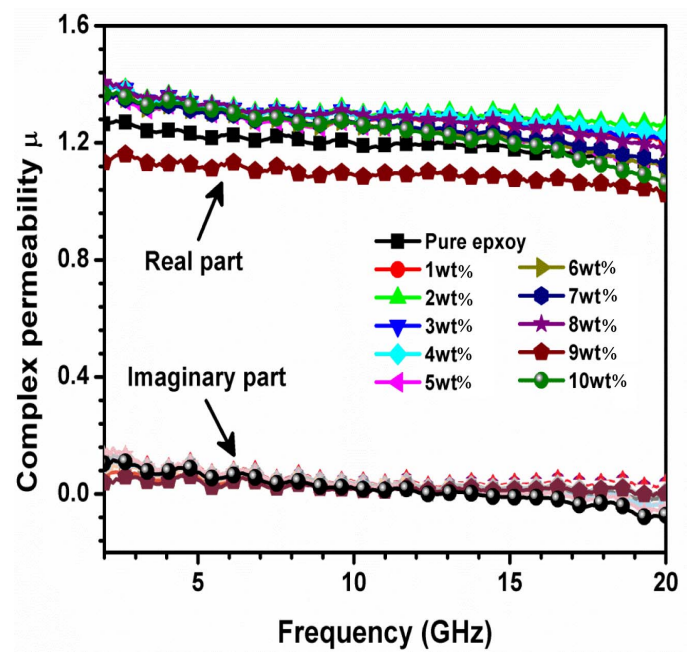

Figure 6. Complex permeability $\mu$ of the MWCNTs-epoxy composite samples. 


$$
\begin{gathered}
R=\left|S_{11}\right|^{2}=\left|S_{22}\right|^{2} \\
T=\left|S_{21}\right|^{2}=\left|S_{12}\right|^{2} \\
A=1-R-T
\end{gathered}
$$

where $S_{11}\left(\right.$ or $S_{22}$ ) and $S_{21}$ (or $S_{12}$ ) are the scattering parameters measured by the Agilent Vector Network Analyzer. In this work, we obtained the absorption ratio of the MWCNTs-epoxy composite samples to microwave radiation for the frequency range of $2-20 \mathrm{GHz}$.

Hence, the absorption ratio $A$ can be used as a measure of the microwave absorption efficiency of the material. The higher the value of $A$ is, the stronger the microwave absorbing ability of the composites will be.

Figure 7 shows the frequency dependence of microwave absorption ratio of the MWCNTs-epoxy composite samples. All the samples have the same thickness of 2 $\mathrm{mm}$. The absorption ratios are much enhanced as the MWCNTs loadings increase in the composite samples in the measured frequency range from $2-20 \mathrm{GHz}$. For the composite samples with MWCNTs loadings from 1 to 3 $w t \%$, the absorption ratio gradually increases in the measured frequency range. For the MWCNTs-epoxy composite samples with MWCNT loadings higher than $4 \mathrm{wt} \%$, the absorption ratios substantially increased. The absorption ratio also shows frequency-dependence. Especially, for the composite sample with $8 \mathrm{wt} \%$ MWCNT loading, the absorption ratio is $6 \%$ at $2 \mathrm{GHz}$, increases to $11 \%$ at $10 \mathrm{GHz}$, and reaches $26 \%$ at $20 \mathrm{GHz}$. For the composite sample with $10 \mathrm{wt} \%$ MWCNT loading, the absorption ratio reaches $23.0 \%$ at $20 \mathrm{GHz}$. It is noticed that the microwave absorption ratio of the composite sample with MWCNT loading of $10 \mathrm{wt} \%$ did not have much improvement in comparison with the composite sample with 8 $w t \%$ MWCNT loading. This indicates that the microwave

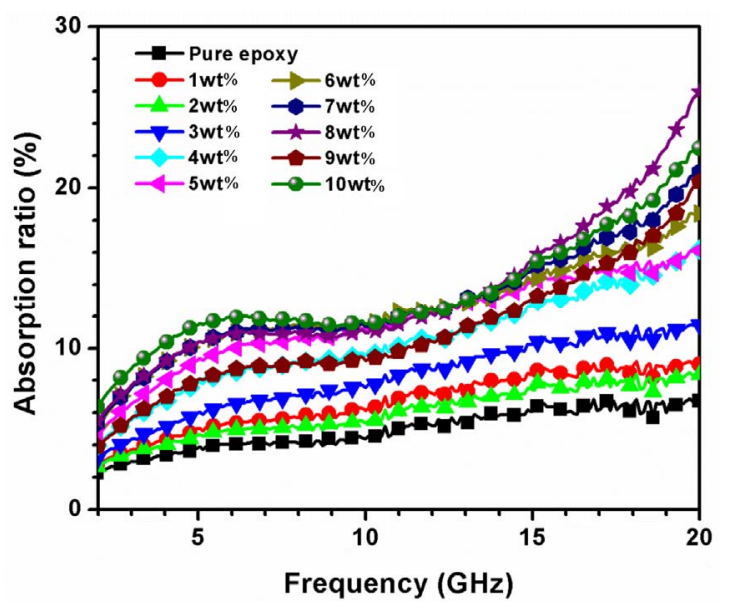

Figure 7. Absorption ratio of the MWCNTs-epoxy composite samples in the microwave frequency range from $2-20$ GHz. absorption ratio in the MWCNT-epoxy composite may be optimized at MWCNT loading of $8 \mathrm{wt} \%$.

\subsection{Microwave Absorption Mechanism}

The individual MWCNTs and MWCNT bundles in the epoxy composite samples can absorb the microwave energy and attenuate the radiation via the interaction between interior electrons and exterior microwave radiation. It has been reported that the defects in CNTs can act as polarization centers and contribute to strong microwave absorption. Compared with single-walled CNTs, MWCNTs have more defects due to their complicated structures (This is confirmed in XRD analysis) and show better microwave absorption, which is mainly attributed to the dielectric relaxation [1]. For the composite samples with 1 $\mathrm{wt} \%$ MWCNTs loading, the sample shows a microwave absorption ratio of $2 \%$ at $2 \mathrm{GHz}$ and $6.5 \%$ at $20 \mathrm{GHz}$. As seen from Figure 1, the individual MWCNTs spontaneously attract each other due to the Van der Waals force between them and form into MWCNT bundles, which are uniformly dispersed in the MWCNTs-epoxy composite. However, the real and imaginary parts of permitivity of MWCNTs-epoxy composites with $1 \mathrm{wt} \%$ MWCNT loading show only a slight increase, in comparison with that of pure epoxy. This indicates that the main microwave absorption of the composite may be attributed to individual MWCNTs and MWCNT bundles, due to the electric relaxation of MWCNTs in the MWCNTs-epoxy composites. As the loading fraction increasing, the MWCNTs spontaneously form larger aggregates and agglomerates. Meanwhile, the permittivity of the MWCNTsepoxy composites increases as the MWCNTs loading increases. It can be seen that the imaginary part (energy loss) of permittivity and loss tangent of MWCNTs-epoxy composites with MWCNTs loadings higher than $4 \mathrm{wt} \%$ are substantially increased and also show frequency-dependence that resembles the absorption ratio of the MWCNTsepoxy composites. Hence, we conclude that the main microwave absorption of the MWCNTs-epoxy composites is due to dielectric loss of the composites.

\section{Conclusion}

In this work, we fabricated carbon nanotubes-epoxy composites with MWCNT (outer diameter less $8 \mathrm{~nm}$ ) loadings from 1 to $10 \mathrm{wt} \%$. The microwave absorption properties of the composite samples were measured from 2 to $20 \mathrm{GHz}$. The results showed that the microwave absorption ratio of the MWCNTs-epoxy composite samples strongly depend on the MWCNT loadings in the composites. The microwave absorption ratio up to $20 \%-26 \%$ around $18-20 \mathrm{GHz}$ was reached for the samples with 8 $10 \mathrm{wt} \%$ MWCNT loadings. The microwave absorption 
of the MWCNTs-epoxy composites is mainly due to the dielectric loss of the microwave field in the composites.

\section{Acknowledgements}

The work is funded in part by the Air Force Office of Scientific Research (Award No FA9550-09-1-0367 and FA9550-11-1-0330), the National Science Foundation (Award No CBET-0754821), and NSF LASIGMA Project (Award No. EPS-1003897, NSF92010-15-RII-SUBR).

\section{REFERENCES}

[1] F. Qin and C. Brosseau, "A Review and Analysis of Microwave Absorption in Polymer Composites Filled with Carbonaceous Particles," Journal of Applied Physics, Vol. 111, No. 6, 2012, Article ID: 061301. doi:10.1063/1.3688435

[2] C. Xiang, Y. Pan, X. Liu, X. Sun, X. Shi and J. Guo, "Microwave Attenuation of Multiwalled Carbon NanotubeFused Silica Composites," Applied Physics Letters, Vol. 87, No. 12, 2005, Article ID: 123103. doi:10.1063/1.2051806

[3] Y. Zhai, Y. Zhang and W. Ren, "Electromagnetic Characteristic and Microwave Absorbing Performance of Different Carbon-Based Hydrogenated Acrylonitrile-Butadiene Rubber Composites," Materials Chemistry and Physics, Vol. 133, No. 1, 2012, pp. 176-181.

doi:10.1016/j.matchemphys.2012.01.004

[4] J. Chang, G. Liang, A. Gu, S. Cai and L. Yuan, "The Production of Carbon Nanotube/Epoxy Composites with a Very High Dielectric Constant and Low Dielectric Loss by Microwave Curing," Carbon, Vol. 50, No. 2, 2012, pp. 689-698. doi:10.1016/j.carbon.2011.09.029

[5] H. Zhang, G. Zeng, Y. Ge, T. Chen and L. Hu, "Electromagnetic Characteristic and Microwave Absorption Properties of Carbon Nanotubes/Epoxy Composites in the Frequency Range from 2 to $6 \mathrm{GHz}$," Journal of Applied Physics, Vol. 105, No. 5, 2009, Article ID: 054314. doi: $10.1063 / 1.3086630$

[6] W. Bauhofer and J. Z. Kovacs, "A Review and Analysis of Electrical Percolation in Carbon Nanotube Polymer Composites," Composites Science and Technology, Vol. 69, No. 10, 2009, pp. 1486-1498. doi:10.1016/j.compscitech.2008.06.018

[7] L. Deng and M. Han, "Microwave Absorbing Performances of Multiwalled Carbon Nanotube Composites with Negative Permeability," Applied Physics Letters, Vol. 91, No. 2, 2007, Article ID: 023119. doi:10.1063/1.2755875

[8] P. C. P. Watts, D. R. Ponnampalam, W. K. Hsu, A. Barnes and B. Chambers, "The Complex Permittivity of Multiwalled Carbon Nanotube-Polystyrene Composite Films in X-Band," Chemical Physics Letters, Vol. 378, No. 5-6, 2003, pp. 609-614. doi:10.1016/j.cplett.2003.07.002

[9] C. A. Grimes, C. Mungle, D. Kouzoudis, S. Fang and P. C. Eklund, "The $500 \mathrm{MHz}$ to $5.50 \mathrm{GHz}$ Complex Permitivity Spectra of Singlewall Carbon Nanotube-Loaded
Polymer Composites," Chemical Physics Letters, Vol. 319, No. 5-6, 2000, pp. 460-464. doi:10.1016/S0009-2614(00)00196-2

[10] J. N. Coleman, U. Khan, W. J. Blau and Y. K. Gun'ko, "Small but Strong: A Review of the Mechanical Properties of Carbon Nanotube-Polymer Composites," Carbon, Vol. 44, No. 9, 2006, pp. 1624-1652. doi:10.1016/i.carbon.2006.02.038

[11] J.-O. Lee, J.-R. Kim, J.-J. Kim, J. Kim, N. Kim, J. W. Park, K.-H. Yoo and K.-H. Park, "Magnetoresistance and Differential Conductance in Multiwalled Carbon Nanotubes," Physical Review B, Vol. 61, No. 24, 2000, pp. R16362-R16365. doi:10.1103/PhysRevB.61.R16362

[12] J. Wu and L. Kong, "High Microwave Permittivity of Multiwalled Carbon Nanotube Composites," Applied Physics Letters, Vol. 84, No. 24, 2004, p. 4956. doi:10.1063/1.1762693

[13] Y. Huang, N. Li, Y. Ma, F. Du, F. Li, X. He, X. Lin, H. Gao and Y. Chen, "The Influence of Singlewalled Carbon Nanotube Structure on the Electromagnetic Interference Shielding Efficiency of Its Epoxy Composites," Carbon, Vol. 45, No. 8, 2007, pp. 1614-1621. doi:10.1016/j.carbon.2007.04.016

[14] P. Avouris, "Carbon Nanotube Electronics and Photonics," Physics Today, Vol. 62, No. 1, 2009, pp. 34-40. doi:10.1063/1.3074261

[15] C. Wang, X. Han, P. Xu, X. Zhang, Y. Du, S. Hu, J. Wang and X. Wang, "The Electromagnetic Property of Chemically Reduced Graphene Oxide and Its Application as Microwave Absorbing Material," Applied Physics Letters, Vol. 98, No. 7, 2011, Article ID: 072906. doi:10.1063/1.3555436

[16] D.-L. Zhao, J.-M. Zhang, X. Li and Z.-M. Shen, "Electromagnetic and Microwave Absorbing Properties of Co-Filled Carbon Nanotubes," Journal of Alloys and Compounds, Vol. 505, No. 2, 2010, pp. 712-716. doi:10.1016/j.jallcom.2010.06.122

[17] T. H. Ting, Y. N. Jau and R. P. Yu, "Microwave Absorbing Properties of Polyaniline/Multi-Walled Carbon Nanotube Composites with Various Polyaniline Contents," Applied Surface Science, Vol. 258, No. 7, 2012, pp. 31843190. doi:10.1016/j.apsusc.2011.11.061

[18] Z. Liu, G. Bai, Y. Huang, F. Li, Y. Ma, T. Guo, X. He, X. Lin, H. Gao and Y. Chen, "Microwave Absorption of Singlewalled Carbon Nanotubes/Soluble Cross-Linked Polyurethane Composites," The Journal of Physical Chemistry C, Vol. 111, No. 37, 2007, pp. 13696-13700. doi:10.1021/ip0731396

[19] C. Brosseau, F. Boulic, P. Queffelec, C. Bourbigot, Y. Le Mest, J. Loaec and A. Beroual, "Dielectric and Microstructure Properties of Polymer Carbon Black Composites," Journal of Applied Physics, Vol. 81, No. 2, 1997, pp. 882891. doi:10.1063/1.364173

[20] C. Brosseau, P. Molinie, F. Boulic and F. Carmona, "Mesostructure, Electron Paramagnetic Resonance, and Magnetic Properties of Polymer Carbon Black Composites," Journal of Applied Physics, Vol. 89, No. 12, 2001, pp. 8297-8310. doi:10.1063/1.1371938 
[21] B. Françoise, B. Christian, M. Y. Le, L. Jean and C. François, "Absorbency Properties and Electron Paramagnetic Resonance Characterization of Polymeric Carbon Black Composites," Journal of Physics D: Applied Physics, Vol. 31, No. 15, 1998, p. 1904. doi:10.1088/0022-3727/31/15/020

[22] L. Zong, S. Zhou, R. Sun, L. C. Kempel and M. C. Hawley, "Dielectric Analysis of a Crosslinking Epoxy Resin at a High Microwave Frequency," Journal of Polymer Science Part B: Polymer Physics, Vol. 42, No. 15, 2004, pp. 2871-2877. doi:10.1002/polb.20154

[23] S. Osaki, "Microwave Frequency Dielectric Properties of Poly(vinylidene Fluoride) Films," Journal of Polymer Science Part B: Polymer Physics, Vol. 33, No. 4, 1995, pp. 685-690. doi:10.1002/polb.1995.090330417

[24] K. J. Vinoy and R. M. Jha, "Radar Absorbing Materials: from Theory to Design and Characterization," Kluwer Academic Publishers, Boston, 1996. doi:10.1007/978-1-4613-0473-9

[25] Z. Li, Z. Ye, J. A. Roberts and G. L. Zhao, "Measurements of Electromagnetic Wave Absorption Properties of Carbon Nanotube-Epoxy Composites at Microwave Frequencies around $8.43 \mathrm{GHz}$," Journal of Applied Physics, Vol.
110, No. 7, 2011, Article ID: 074107-074105. doi:10.1063/1.3646405

[26] Z. Ye, Z. Li, J. A. Roberts, P. Zhang, J. T. Wang and G. L. Zhao, "Electromagnetic Wave Absorption Properties of Carbon Nanotubes-Epoxy Composites at Microwave Frequencies," Journal of Applied Physics, Vol. 108, No. 5, 2010, Article ID: 054315. doi:10.1063/1.3477195

[27] Z. Liu, G. Bai, Y. Huang, Y. Ma, F. Du, F. Li, T. Guo and Y. Chen, "Reflection and Absorption Contributions to the Electromagnetic Interference Shielding of Singlewalled Carbon Nanotube/Polyurethane Composites," Carbon, Vol. 45, No. 4, 2007, pp. 821-827. doi:10.1016/j.carbon.2006.11.020

[28] A. R. Von Hippel, "Dielectrics and Waves," Artech House, Boston, 1995.

[29] R. W. P. King, "Transmission-Line Theory," McGraw-Hill, New York, 1955.

[30] P. Saini, V. Choudhary, B. P. Singh, R. B. Mathur and S. K. Dhawan, "Polyaniline-MWCNT Nanocomposites for Microwave Absorption and EMI Shielding," Materials Chemistry and Physics, Vol. 113, No. 2-3, 2009, pp. 919926. doi:10.1016/j.matchemphys.2008.08.065 